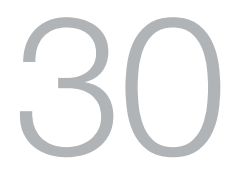

\title{
Fiji: Reflections in the Infinity Pool
}

\section{John Connell}

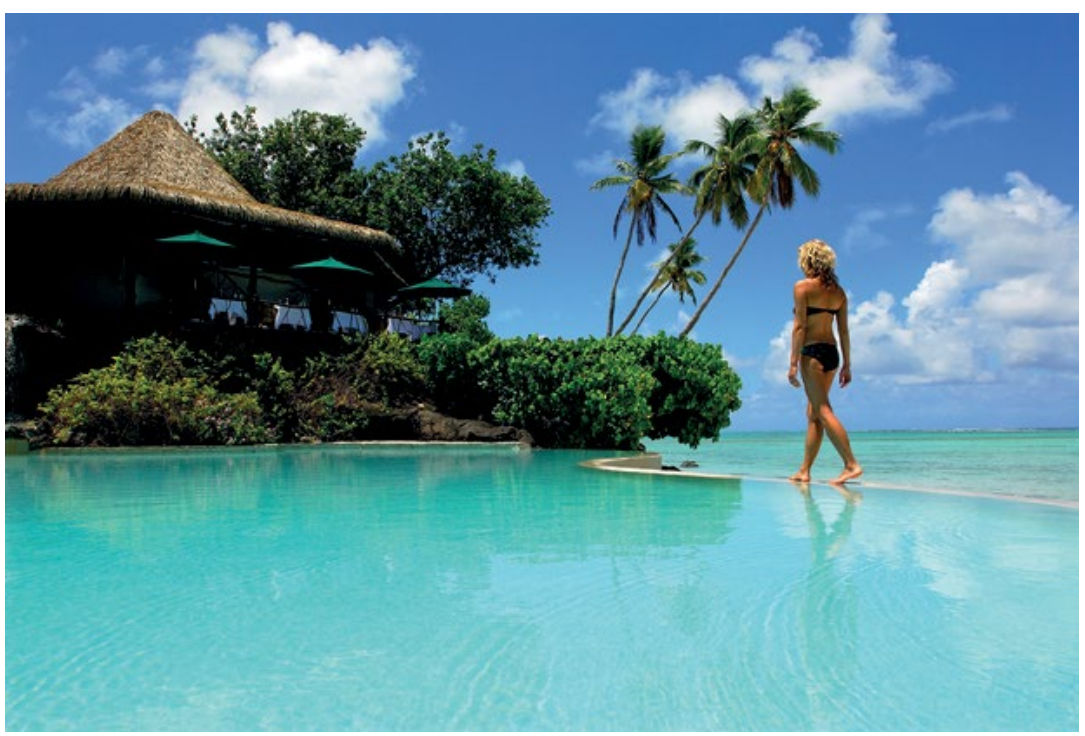

Figure 131. An infinity pool.

Source. Photo by Pacific Resort Hotel Group, Pacific Resort Aitutaki, Cook Islands and used with permission.

The infinity pool extends into the distance beyond blue seas and under blue skies - the rest of the world and its indignities are banished beyond the horizon and space is seemingly endless-until only another distant island intrudes. Purpose-built pools in small islands, 
naturally surrounded by water, constitute the ultimate architecture of pleasure. The sea is domesticated-harmful creatures are gone, abrasive corals are absent, waves and currents are without threat. Tourism is a sentient, stress-free, mildly emotional experience.

The lure of water is everywhere: water is therapy, it anchors resort existence - warm, clean, soothing, languorous, soporific even. In the midst of a sea of islands - resort and landscape blend together, into the increasingly bland face of island tourism, where any sense of place has gone.

The tourist Pacific has come to exemplify placelessness - ironic and even paradoxical here, when smiling Fijians grace every brochure-yet resorts isolate visitors and tourists in ever strengthening cocoons and bubbles, a small ' $\mathrm{p}$ ' pacific rather than a distinctive and differentiated Pacific.

Reflections on space and place are drawn from five years of Australian newspaper articles on Fiji (2009-13), a suite of contemporary (mid-2014) websites and multiple current travel brochures, simply differentiated as newspaper (N), website (W) and brochure (B) since all conspire and combine to create a distinctive, introspective world of infinite pleasure and uninhibited delight. They are repetitious in an uncritical journalistic and PR oeuvre that knows only positives and superlatives, and that rarely offers alternative or critical discourses. Specific sites and stories have largely been rendered anonymous, to protect the guilty.

\section{Advertising islands}

Promoting Fiji as a tourist destination has always involved three themes: tropical island South Seas imagery, cultural and scenic attractions unique to Fiji, and experiences quite distinct from urbanised metropolitan lifestyles. ${ }^{1}$ These have scarcely changed in half a century, but have intensified, gone upmarket, displaced culture and rebalanced Fiji from the mainland to small outlying islands and

1 Stephen G. Britton, 1983, Tourism and Underdevelopment in Fiji, Monograph No. 31, Canberra: Development Studies Centre, The Australian National University, p. 36. 
resorts. ${ }^{2}$ Through that process place has faded away. While resorts are certainly in Fiji, they are not necessarily of it. Brochures and websites rarely offer even the most diagrammatic of maps. Only fine print (or 'an easy helicopter trip from Nadi') suggest an actual location.

'Fiji: the way the world should be' (taken up directly by more than one resort) has been the longest standing national marketing slogan. Though ironic in a nation that has been dealt recurrent coups and economic crises, it has served the country well. And silenced and excluded the daily world. Coups and crises are another world: all the more reason to be apart from that. So utopian adjectives are overworked, clichés pile up and hyperbole abounds - pristine, blissful, unique, exclusive, peaceful-'Palm trees with the obligatory hammock hanging from them' (N)-as Fiji gently disappears.

In the midst of generic attributes there are only rare mentions of Fiji: 'a true island oasis, Fiji is an intoxicating land' (B). Elsewhere destinations are 'in the heart of the Pacific' (W), 'the ultimate island paradise' (B), 'impenetrable jungle, coconut plantations and amazing coral reefs' (B), 'if the untouched South Pacific is what you seek then you'll find it' (B), and 'our own little piece of paradise' (W).

Tourism is shaped by the picturesque. Resorts are only exceptionally located in place - 'a small market town is nearby' (W)-but more frequently 'nestled amongst tropical gardens' (W) or 'set on a coral and sand-fringed atoll within a vibrant marine sanctuary' (W). Natural landscapes abound, typically remote from markets and towns. Coconut palms sway, crabs scuttle and fish glide through variously azure, turquoise, ultramarine and (albeit on one occasion) Listerine blue waters. 'This Eden like isle is ringed by tropical waters' (W) or perhaps by 'our trademark aqua waters' (W). This combines into 'an idyllic location for discerning travellers seeking an exotic beachside getaway' (W). So much is tropical-universal that Fiji gradually recedes into infinity.

Banal and mundane 'destination branding' ensures similarity rather than marking any distinctive island experience; 'mainlands' are small enough to become islands, and resorts are increasingly all-embracing.

2 John Connell, 2015, 'Competing islands? The Mamanuca and Yasawa Islands, Fiji', in Archipelago Tourism. Policies and Practices, ed. Godfrey Baldacchino, pp. 183-97, Farnham: Ashgate. 
Treasure Island is one of Fiji's most iconic resorts, with extensive experience in providing hospitality and friendship to travellers from across the globe. This resort is specially designed for honeymooners, couples and families seeking a unique and unforgettable island holiday experience (B),

which covers most possibilities. On the next page of the brochure, Castaway Island is described as

an iconic private island and one of the most popular resorts in the Mamanucas. Surrounded by white sandy beaches with a pristine natural environment, vibrant coral reefs and a great resort atmosphere ... the perfect escape for families and couples alike (B).

The extent of differentiation between such resorts is trivial. Repetitive descriptions and positive attitudes proliferate and degenerate into an amorphous mass where the attributes of particular islands are minimised with reference to descriptions of the resort itself. Water soothes and surrounds. Words wash by like waves. The island world is awash with images that conform with, confirm and reinforce tourist expectations. Islands and resorts are different yet familiar, everywhere but nowhere.

\section{Islands apart}

Despite the need for ease of accessibility, separation is necessary to invoke difference and even exclusiveness, hence repeated invocations to 'charming and remote' (B), 'blissful isolation' (B) and 'A sense of privilege and exclusion, of blissful isolation from the rest of the world' (N). Creative destination branding becomes introspective and rather less than innovative.

Solitude and separation engender peace: 'Sail to uninhabited tropical islands, anchor in private lagoons' (B) where the resort 'epitomises the seclusion and graceful hospitality for which the Fijian archipelago is famed' (W). The Pacific polis is now without danger, terrestrial or marine. It has become 'A place with no crowds, commitments or deadlines. A place where you can be yourself and re-connect with the natural way of life while being wrapped in luxury and romance. Wake up to the sound of whistling birds and magical rain forests. Unwind, relax and submerge yourself in the simplicity of pristine tropical paradise sanctuary' (W). 
To meet 'your desire for seclusion, for splendour, for authenticity' (W) several resorts have simply banished others, or imposed numerical constraints. Resorts may cater to couples only, hopefully 'romantic couples' (if not- 'rekindle the romance' (W)), while others exclude children under 16, or are off-limits to non-guests. 'Tokoriki prides itself on being an idyllic adults-only retreat for those who want to escape the stresses of everyday life, swapping offices and commuting for a week or two of non-stop luxury' (W). Luxury may even be defined as the absence of others. 'Whatever you choose to do at Yasawa, you'll do it in complete seclusion' (W). Better still 'why book a hotel room when you can have an entire island?' (W). And even better again: on Turtle Island, 'this entirely all-inclusive, exotic tropical paradise can be rented for a week at a time' (W). Pleasure derives from the absence and exclusion of others.

Air-conditioning and surround sound exclude the world. Seclusion and isolation offer social stability, safety and sameness - a fleeting release from the seething, congested capitalist maelstrom into a demographically diminished world.

\section{Pristine}

Tourism takes place in an environment that naturally is neither tarnished nor trashed by capitalism. Pollution is far beyond such an innocent, unchanging landscape. Indeed 'it appears as if the garden of Eden does exist after all' (W). All that is predictable: 'spend a single moment here ... and you will be convinced that the words "paradise found" were first spoken with our secluded beaches and authentic luxury in mind' (W), 'a pristine aqua lagoon and dazzling white sand beach' (W), 'lush tropical vegetation surrounded by white sandy beaches' (N). 'Once upon a time across the bluest of oceans, an island was born of lava and sand - an untouched paradise whose heart was a turquoise lagoon of unimaginable beauty and tranquility. The first visitors came and explored' (W) yet must have left no imprint.

Of course, once again, it is advisable to escape other tourists, their tawdry resorts and their worlds. Away from over-populated tourist destinations and the frantic pace of preoccupied modern living ... another world. This is not just escapism, more a return to nature' (W) but a once-wild nature, tamed, subdued and rendered sublime. 
One resort is 'the last pristine place on earth' (W) and 'paradise perfected' (W); since nightly rates start at US\$2,280 it may be that 'fantasy becomes reality' (W).

Resorts are created and designed to 'blur the boundary between architecture, interiors and landscape' $(\mathrm{N})$, as interior and exterior are fused, to evoke an ethos of simplicity that might capture a supposedly idyllic past time. 'It is a unique and special place designed with integrity to Fijian cultural values, traditional designs and architecture, and is embraced by the renowned warmth of the Fijian people' (W). The core of resorts is the mock bure (traditional thatched Fijian house) in a sanitised paradise with invisible modernity. 'Likuliku embodies the richness of an ancient culture with vibrant present-day lifestyle touches. Welcome to Fiji's most unique luxury escape for couples. Welcome to your magical sanctuary' (W). Bures evoke 'nostalgia, fantasy and the exotic'. ${ }^{3}$ Likuliku is 'built and decorated in the traditional island style, located directly on stilts in the water, on the beachfront' (W), although 'traditional' islanders were far too wary of the vagaries of oceans and cyclones to build anything close to the coast.

Architecturally choreographed views across pools and oceans extend to the 'horizon aflame with the kind of sunset you might see in a brochure' $(\mathrm{N})$. And is seen in brochures. Mimicry is multiplied. 'I watch the sun slowly set from my plunge pool' (N) and 'I'm in love with the salt infinity pool that has all the dreaminess of a larger resort pool while being small enough to feel like your own back yard in paradise' (W). 'There are no clouds, the sky is crystal clear and there's nothing between me and the big blue sea' (N). 'The dream of an unworked natural landscape is very much the fantasy of people who have never themselves had to work the land to make a living. ${ }^{4}$ Such is readily evident and actively constructed.

3 Brian King and Peter Spearritt, 2001, 'Resort curtilages: The creation of physical and psychological tourism spaces', in Virtual Globalization. Virtual Space/Tourist Space, ed. David Holmes, pp. 245-61, London: Routledge, p. 252.

4 William Cronon, 1995, 'The trouble with wilderness: Or, getting back to the wrong nature', in Uncommon Ground: Rethinking the Human Place in Nature, ed. William Cronon, pp. 69-90, New York: Norton, p. 80. 


\section{Timeless}

Locked into a natural pristine environment, tourism is quite timeless: 'Where would you go if you just wanted to turn the world off? This is it' $^{\prime}(\mathrm{W})$ and so experience 'no idea what day or time it is' (W). History is banished into infinity where nothing changes or is likely to change: 'just as the mainland of Viti Levu was like 50 years ago' (W) is as close as it gets.

Tourists are constantly enjoined to embrace 'Fiji time', abandon watches and the internet, since 'everything here happens in Fiji time' (N) or simply 'island time'. That then means that 'Time seems to slow down as I adjust to the easy-going rhythm' (N). With luck the present becomes timeless. 'Time has a way of dissolving on a tropical island' (N). Even in the timeless tropics going back in time is invaluable.

'Being out in nature brings a chance to realign yourself with some of the deepest roots of being. Build your day around the rhythms of the day. Forget clock-time, and make time to respond to what the day presents you. The greatest symphony in the world happens as the predawn light rises into day and the sun come up to the song of birds' (W). 'Stop, take a deep breath and let life pass by' $(\mathrm{N})$. Technology is unstated but subtly presumed. Money itself is unnecessary at the most upmarket resorts: a modern subsistence world. The landscape has been tamed, appropriated and rendered authentic.

\section{Languid}

Without time urgency disappears. 'Calm warm turquoise water is as close to the perfect tropical moment I've experienced' $(\mathrm{N})$. Water is the real and metaphorical key: 'immerse yourself in a realm of relaxation' and 'retreat to the serenity' (W), or more generally 'immerse yourself in award-winning luxury' (W). For this provides opportunities, while 'surrounded by serenity' (W) to 'wash the soul' (W), 'awaken the senses' (W) and 'rejuvenate the mind body and spirit' (W) or merely relax and indulge.

Activity is condoned but scarcely encouraged. 'Do as much or as little as you like. We'll help you slot in to your zone of yearning' (W). Quite so. 'If you are seeking to do more than just relax and soak up the sun [we] 
offer numerous activities to give you a memorable touch of adventure in paradise' (W). These are islands of consumption not production, other than of handicrafts, where resorts stage 'performances' of handicraft manufacture, and 'local people will bring their fascinating handicrafts to you' (W) just frequently enough to provide a measure of cultural capital and a few photographs. Organised excursions and beach activities exist but, as so much is built in (three meals a day, golf courses, kava ceremonies and more), that endeavour and leaving the resort are slightly improbable.

Trivial connections, whether of environment, society or economy, embrace the local. Only occasionally does 'culture' intrude. 'Immerse yourself in a Pacific cultural experience at the Marau Village. Enjoy a lavish lovo feast of Fijian specialties cooked in earth ovens (lovo). The evening opens with our exotic Polynesian dance performances and knife and fire dancing show by the Shangri-La Fijian Firedancers and culminates with the Fijian Beqa firewalkers showcasing the mystical art of firewalking' (W). Water reconstitutes jaded bodies, where spas might draw on suggestions of tradition and timelessness: 'indulgent treatments inspired by ancient wisdoms and healing traditions' (W). 'Its modern and traditional treatments draw on indigenous plants and herbs that have been used to heal for generations' (W) with 'warm seashell massage, banana leaf wraps, locally produced virgin coconut oil' (W). But, failing that, 'a total spa escape and ritual to allow your mind and body to be rejuvenated, replenished and nourished' (W). 'The day spa is incredible, to be pampered by skilled spa therapists whilst listening to the sounds of a waterfall' (W). Waterfalls and shops are drawn indoors, precluding any need to venture beyond. Spectacle, performance and purchases are internalised as the resort gradually evolves into theme park.

A glorified global may intrude selectively. 'Incorporating traditional Fijian bure architecture with Balinese pavilion architecture [to] feature open plan layout, taking advantage of the spectacular views creating fluid indoor/outdoor ambience while ensuring complete privacy' (W). One resort is named as 'a Tibetan exclamation of wonder' (W). Globalism is inevitable where the Pacific scales few cuisine peaks, 'island nights' of local specialties can disappoint (though 'Native foods are worth a taste' (B)) yet good food and wine are integral components of good tourism. Menus do find Pacific adjectives and 'the recipes are inspired by a distinctive culinary style blending international gourmet 
cuisine with traditional Fijian flavours. The meals are a true reflection of the colourful tropical setting [and] the retreat's own organic garden' (W). More probably 'Dishes are infused with Polynesian, European, Chinese and Indian flavours, often with a tropical twist for authentic Fijian flair' (B) or 'The menu does a carousel from Japan to Vietnam to Italy and France' (N). International chefs can produce a 'signature crabmeat omelet' matched by a 'fine wine list' balanced by a lagoonfacing spa $(\mathrm{N})$ : 'island warmth mixed with western savoir-faire' $(\mathrm{N})$. Introspection and infinity collude.

\section{Displaced islanders}

It is a cliché that islanders and culture are a backdrop - though IndoFijians are neither to be seen nor referred to-but are necessarily and helpfully there: 'a unique nation of colourful religious festivals, ritualistic tribal ceremonies and fascinating archaeological finds' (B) with 'sacred space, ancient wisdom' (W). Kava ceremonies and meke dances are inescapable. No resort is without a cultural performance of impressive and noisy staged inauthenticity, contemporary examples of Boorstin's (1964) 'pseudo-event'. ${ }^{5}$ 'Watch the children dance their traditional spear-waving war dance with gentle movements' (W); an implausible tradition is constantly reinvented as the soft primitivism of good savages. ${ }^{6}$ The exotic is tamed, lingering only as painted performance faces and hibiscuses behind the ear. Smiles and 'bula' are minimalist place markers of tourism: the 'commodification of the smile $^{7}{ }^{7}$

Islanders serve and smile, yelling bula (hello), paddling canoes and child-minding, having made the painless transition from ancient warriors and cannibals (whose sanitised knives and forks make kitsch souvenirs) to the way the world should be. 'Come and be pampered, our caring Fijian staff are here to make your stay unforgettable' (W)

5 Daniel J. Boorstin, 1964, The Image. A Guide to Pseudo-Events in America, New York: Harper.

6 Yoko Kanemasu, 2008, 'Weapons of the workers. Employees in the Fiji hotel scene', in Tourism at the Grassroots: Villagers and Visitors in the Asia-Pacific, ed. John Connell and Barbara Rugendyke, pp. 114-30, London: Routledge, p. 114.

7 Miriam Kahn, 2011, Tahiti. Beyond the Postcard: Power, Place and Everyday Life, Seattle: University of Washington Press, p. 146; Kanemasu, 'Weapons of the workers'. 
while 'Our friendly and discreet butler is everywhere' (W) all part of 'a revolving cast of smiling wait staff, a seamless parade of polite Fijians' (N). Infinity acquires human dimensions.

The revolving cast, and unobtrusive locals who know their place, ensure there is no sense of real participation, perception, understanding and belonging. Perhaps there is scope to tangle with an idealised environment: on Taveuni 'I've discovered the real Fiji, where villagers still feel at home, fishing, planting their gardens, thatching bures and hunting wild boar' $(\mathrm{N})$. But adult social interaction is missing and tourism is isolated from any real Fiji. Fortuitously, while tourism rarely intrudes into that world, it makes some beneficial financial contribution to it, even stimulating environmental management, especially in smaller, more remote islands. ${ }^{8}$ But it is a suppliant, menial and uneven form of development that has provoked a quiet and subtle Fijian resentment towards servicing the leisure aristocracy. ${ }^{9}$

\section{Tourism in infinity}

As imagery and practice move upmarket, an infinity begins to separate tourists from Fiji, which lies further beyond a physical and psychological horizon. Tourist gazes are directed into space and ignore the local place. Fiji has become a generic Pacific — as place is gradually abolished - crushed under the weight of multimedia imagery. Resorts represent narratives of loss - and the simultaneous disappearance of culture, history and geography - and of authenticity - tradition has been reinvented over and over again, until nothing is left. Only pseudo-events in non-places remain. ${ }^{10}$

In a global age we withdraw and are encouraged to withdraw into ourselves and into sybaritic luxury. This is no place of distinctive culture - nothing more than a familiar, generic destination-static, immobile, sheltered even from the Pacific. The expense of isolation and exclusivity has permitted luxuriant anonymity. Dream, imagine and relax. Participate energetically and beyond only if you must.

8 Connell, 'Competing islands?'

9 Kanemasu, 'Weapons of the workers'.

10 Marc Augé, 1995, Non-Places. Introduction to an Anthropology of SuperModernity, London: Verso. 
Islanders and children are absent, unless servants or photogenic objects, for these are places of middle-class, middle-aged solace and morality - and of indolence, isolation and privacy. Enclosed resorts are introspective pseudo-places - preferable to 'real' places and real experiences - a determined and organised retreat from everyday life, replicating familiar pleasures through an ensemble of standardised and barely differentiated components. Image subsumes and overwhelms novelty and difference.

Resorts are designed and described to satisfy anticipated gazes with just enough that is exotic to hint at difference. Yet innocent plagiarism and infinite clichés, and the uniformity of advertisements, of language and of smiles, are underpinned by repetition and familiarity, creating one more category of non-places, gradually devoid of local specificity within the super-modern leisure world. Island resorts are the spaces typically encountered when travelling, to be marketed, portrayed, experienced and remembered in generic terms. Unique no longer. Connection with place is fading fast. Culture cannot linger in nonplaces. Islands and resorts vary and though each has particular attributes, all are subsumed into a pleasure periphery. Difference is demarcated by the materiality of commerce - and price - rather than by physical and social landscapes. Space, time and Fiji are eroded, empty of meaning, vanquished and vanished into infinity.

\section{References}

Augé, Marc. 1995. Non-Places. Introduction to an Anthropology of SuperModernity. London: Verso.

Baldacchino, Godfrey (ed.). 2015. Tourist Archipelagoes: Policies and Practices. Farnham: Ashgate.

Boorstin, Daniel J. 1964. The Image. A Guide to Pseudo-Events in America. New York: Harper.

Britton, Stephen G. 1983. Tourism and Underdevelopment in Fiji. Monograph No. 31. Canberra: Development Studies Centre, The Australian National University. 
Connell, John and Barbara Rugendyke (eds). 2008. Tourism at the Grassroots: Villagers and Visitors in the Asia-Pacific. London: Routledge.

Connell, John. 2015. 'Competing islands? The Mamanuca and Yasawa Islands, Fiji.' In Archipelago Tourism. Policies and Practices, ed. Godfrey Baldacchino, pp. 183-97. Farnham: Ashgate.

Cronon, William. 1995. 'The trouble with wilderness: Or, getting back to the wrong nature.' In Uncommon Ground: Rethinking the Human Place in Nature, ed. William Cronon, pp. 69-90. New York: Norton.

Cronon, William (ed.). 1995. Uncommon Ground: Rethinking the Human Place in Nature. New York: Norton.

Holmes, David (ed.). 2001. Virtual Globalization. Virtual Space/Tourist Space. London: Routledge.

Kahn, Mirian. 2011. Tahiti. Beyond the Postcard: Power, Place and Everyday Life. Seattle: University of Washington Press.

Kanemasu, Yoko. 2008. 'Weapons of the workers. Employees in the Fiji hotel scene.' In Tourism at the Grassroots: Villagers and Visitors in the Asia-Pacific, ed. John Connell and Barbara Rugendyke, pp. 114-30. London: Routledge.

King, Brian and Peter Spearritt. 2001. 'Resort curtilages: The creation of physical and psychological tourism spaces.' In Virtual Globalization. Virtual Space/Tourist Space, ed. David Holmes, pp. 245-61. London: Routledge. 
This text is taken from Touring Pacific Cultures, edited by Kalissa Alexeyeff and John Taylor, published 2016 by ANU Press, The Australian National University, Canberra, Australia. 